Saudi Journal of Medicine

Abbreviated Key Title: Saudi J Med ISSN 2518-3389 (Print) |ISSN 2518-3397 (Online)

\title{
Most Common Additional Risk Factors of Coronary Artery Disease in Smoker Patients Specifically: Shedding Light on Smoker's Angiographic Profile
}

\author{
Shwan Othman Amen ${ }^{1}$, Banan Qasim Rasool ${ }^{2 *}$ \\ ${ }^{1} \mathrm{MD}, \mathrm{PhD}$, Consultant Interventional Cardiologist, Surgical Specialty Hospital - Cardiac Center, Erbil, Iraq
}

${ }^{2}$ M.B.Ch.B, Medical Doctor at Erbil Teaching Hospital, Erbil, Iraq

DOI: $10.36348 /$ sjm.2020.v05i12.007 $\quad$ | Received: 13.12 .2020 | Accepted: 24.12 .2020 | Published: 29.12 .2020

*Corresponding Author: Dr. Banan Qasim Rasool

\section{Abstract}

Background: Smoking is a well-recognized risk factor of CAD, angiographic profile and traditional risk factors among smoker patients varies, along with their clinical presentation and outcome. Objective: This study has been conducted to focus on the angiographic profile of smoker patients presenting with CAD and to explore the prevalence of their additional of risk factors. Method: This study has been enrolled among 328 smoker patients with CAD presenting to ER of SSH-cardiac Center/ Erbil from Jan 2017 to March 2020. Results: The study population was composed of 320 males $(97.6 \%)$ and 8 females $(2.4 \%)$. The mean age was $39.07+12.3$ years, with an age range of $20-75$. The results showed that smoker patients with CAD had occlusive CAD (79.3\%). The prevalence of most commonly occluded artery was LAD (43.8\%) during CoA presenting with AWMI. The prevalence of risk factors was, Hypertension (37.8\%), positive family history $(40.2 \%)$, high levels of LDL (53.7\%), Lowered levels of HDL (31.7\%), elevated levels of TC (31.7\%), elevated levels of TG (29.3\%). It was noted that $29.3 \%$ were Diabetic, and according to the HbA1c levels, of $34.1 \%$ was diabetic, this clarifies that $4.8 \%$ of the smoker patients were undiagnosed DM (Newly diagnosed DM). Conclusion: Smoking is associated with the angiographic profile, traditional risk factors and their clinical outcomes. AWMI was mostly observed among smoker patients owing to LAD lesions.

Keywords: Coronary Artery Disease, Smoking and Cardiovascular Health, LAD occlusion in Smokers, Risk Factors of $\mathrm{CAD}$, Anterior Wall Myocardial Infarction.

Copyright $\odot \mathbf{2 0 2 0}$ The Author(s): This is an open-access article distributed under the terms of the Creative Commons Attribution 4.0 International License (CC BY-NC 4.0) which permits unrestricted use, distribution, and reproduction in any medium for non-commercial use provided the original author and source are credited.

\section{INTRODUCTION}

Coronary Artery Disease is a state of accumulation of atherosclerotic plaques in the coronary arteries, heading to dysfunctioning of the corresponding myocardium, known as Myocardial Infarction (MI). It is a common multifarious public health issue now a days and counted as one of the leading cause of morbidity and Mortality in both developed and developing countries [1].

Epidemiological studies strongly support the assertion that cigarette smoking in both men and women increase the incidence of Myocardial Infarction and Fatal Coronary Artery Disease [2-12]. Even low-tar cigarette and smokeless tobacco have been shown to increase the risk of cardiovascular events in comparison to non-smokers [13, 14].

Cardiovascular diseases are affecting millions of people worldwide, in both developed and developing countries. The death rates attributing to the disease has shown a decline in most of the developed countries in the previous decades, however it is still the leading cause of death and exerts a heavy social and economic toll globally. Similar to many high-income countries during the 20 century, low- and middle-income countries are seeing an alarming increase in the rates of Cardiovascular disease, and this change is accelerating that is responsible for $80 \%$ of global deaths [15]. CAD includes a spectrum of manifestations ranging from asymptomatic atherosclerotic diseases to Acute Coronary Syndrome which includes STEMI, NSTEMI and Unstable Angina.

Smoking has been shown to accelerate atherosclerosis and precipitate AMI by multiple mechanisms, such as (1) increases the levels of serum low-density lipoprotein-cholesterol (LDL-C) and triglyceride concentrations and reduces serum highdensity lipoprotein-cholesterol (HDL-C); (2) stimulates the free radical to oxidize LDL-C molecules, this leads the oxidized LDL-C molecules to accumulate within the arterial wall; (3) induces vascular inflammation 
characteristic of atherosclerosis, as reflected by higher serum C- reactive protein levels in smokers; and (4) The nicotine and free radicals in the cigarette activates the sympathetic nervous system (SNS) and leads increase of heart rate, contractility and wall tension [16].

The nicotine via its hemodynamic effects contributes to acute cardiovascular events, although current evidence suggests that the effects of nicotine are much less important than the prothrombotic effect of cigarette smoking or the effect of carbon monoxide.

Consequently, this increase causes high myocardial oxygen demand to heart. The high activity of SNS due to nicotine effect results in increased oxygen demand to myocardium. The myocardial oxygen flow is decreased through coronary arterial vasoconstriction. In addition, cigarette smoking causes increase in the levels of carboxyhemoglobin in the blood, with the potential to further reduce myocardial oxygen delivery from oxyhemoglobin [16].

In patients with heart disease smoking may cause deterioration in cardiac performance and induces coronary vasoconstriction. Other adverse effects of smoking on cardiovascular system includes an increase in platelet reactivity and an increase in fibrinogen concentration [17].

A clinical trial showed that cigarette smoking plays an important role in Prothrombotic consequences on cardiovascular system [18].

These effects on systemic and coronary hemodynamics, lipid metabolism and hemostasis may contribute to the long term adverse consequences of smoking [17].

These effects are present in almost all of the smoker patients, regardless of any other additional risk factor for CAD.

With addition of any other traditional risk factors for $\mathrm{CAD}$, these impacts might have more effects on the cardiovascular health status.

The association of a positive family history of CAD, Dyslipidemia, Hypertension and Diabetes Mellitus (DM) with smoking is known and all are related to Premature CAD [19-21].

The evidence linking cigarette smoke exposure with cardiovascular disease is clearly present, yet the exact component of cigarette smoke and the mechanism responsible for this association have not been clearly elucidated [22].

Due to the important role of smoking in CAD, this study aimed to update the clinical observations of smoking related cardiovascular disease and to analyze the prevalence of most frequent cardiovascular risk factors in smoker patients. Also to shed light on their Angiographic Profile and Determine most commonly occluded Coronary Artery in smoker patients.
Abbreviations:
AWMI = Anterior Wall Myocardial Infarction
$\mathrm{CAD}=$ Coronary Artery Disease.
$\mathrm{LAD}=$ Left Anterior Descending
RCA $=$ Right Coronary Artery
LCX = Left Circumflex Artery
CoA = Coronary Angiography
HDL $=$ High Density Lipoprotein
LDL $=$ Low Density Lipoprotein
$\mathrm{TG}=$ Triglyceride
TC $=$ Total Cholesterol
INOCAD = Ischemia with No Obstructive
Coronary Artery Disease
$\mathrm{IHD}=$ Ischemic Heart Disease

\section{MATERIALS AND METHODS Study Population}

The study population comprised 328 consecutive patients with Coronary Artery Disease, admitted to the causality department of the Surgical Specialty Hospital - Cardiac Center - within $12 \mathrm{~h}$ of the onset of clinical signs and symptoms from Jan 2017 to March 2020. All patients aged between 20 and 75 years were included in this study. Diagnostic criteria of CAD were followed according to the guidelines of the European Society of Cardiology, such as when the patient is presented with typical chest pain, diagnostic electrocardiogram (ECG) changes, and a significant elevation of cardiac enzymes. Exclusion criteria for patients and controls included pregnancy, anemia, and kidney failure. Patients subsequently underwent coronary angiography and revascularization by either primary PCI or pharmaco-invasive PCI or CABG surgery after obtaining informed consent with Their Family.

\section{Statistical Analysis of Data}

Data were analyzed using the Statistical Package for Social Sciences version 23 (SPSS, IBM, Armonk, NY, USA). Differences in variables were tested using Student's t-tests. $\mathrm{P}<0.05$ was considered statistically significant.

\section{Ethical Consideration}

All the data has been anonymous and not the relevant personal information's of the patients has been shown. The data was not collected from the patients directly, but it was collected from the Admission File of the patients and consent was taken from the Data Registry Department of SSH-Cardiac Center. The patient's personal states, name and other direct indicators have therefor been anonymousized.

\section{Laboratory Analysis}


The serum levels of lipid profile parameters, including total cholesterol (TC), HDL-C, LDL-C, and TG, were determined at the admission of the patient presented with AMI. These laboratory tests were carried out using Cobas c311 chemistry analyzer (Roche Diagnostics, Basel, Switzerland) for sample analysis.

Hyperlipidemia was defined as serum cholesterol of $\geq 200 \mathrm{mg} / \mathrm{dl}$, triglyceride $(\mathrm{TG})>200$ $\mathrm{mg} / \mathrm{dl}$, low-density lipoprotein > $130 \mathrm{mg} / \mathrm{dl}$, HDL-C < $50 \mathrm{mg} / \mathrm{dl}$ for female and $<40 \mathrm{mg} / \mathrm{dl}$ for male, for known cases of dyslipidemia and/or those on medication for dyslipidemia.

Obstructive CAD was defined as $\geq 70 \%$ lesion in major arteries or $\geq 50 \%$ lesion in left main coronary artery. Intermediate disease was defined as $50 \%$ to $69 \%$ stenosis of major arteries. Whereas minimal disease (No critical lesion) was defined as $\leq 50 \%$ lesion, and together they were combined and classified as having non-obstructive disease.

\section{RESULTS}

A total of 328 smoker patients who have been admitted to SSH-Cardiac Center/ Erbil-Iraq, due to one of the manifestations of CAD (STEMI, NSTEMI and Unstable Angina) during the study period was included in this present study, and according to the study parameters their information's has been analyzed. Of the total number on patients included in the study was $320(97.6 \%)$ male, and $8(2.4 \%)$ female. The mean age \pm $\mathrm{SD}$ was $39.07 \pm 12.3$ years, with an age range of 20-75 years old.

The prevalence of CAD among smoker patients was highest among the male age group of 3039 years of age $(55.5 \%)$, then followed by $17.1 \%$ of male patients through age group of 50-59 years of age. While all the included female patients were among 5059 years of age. Interestingly, the prevalence of CAD among very young (20-29 years of age) smoker male patients was $13.1 \%$, while none of the smoker female patients had prevalence of CAD at this rage of age group.

This clarifies that smoking habit with an increased risk for Cardiovascular health have stronger impact at a younger age in males than females. And this showed a statistically significant difference with a $\mathrm{P}$ value of 0.013

Figure one summarizes the prevalence of CAD among smoker patients in relation with Age groups and Gender.

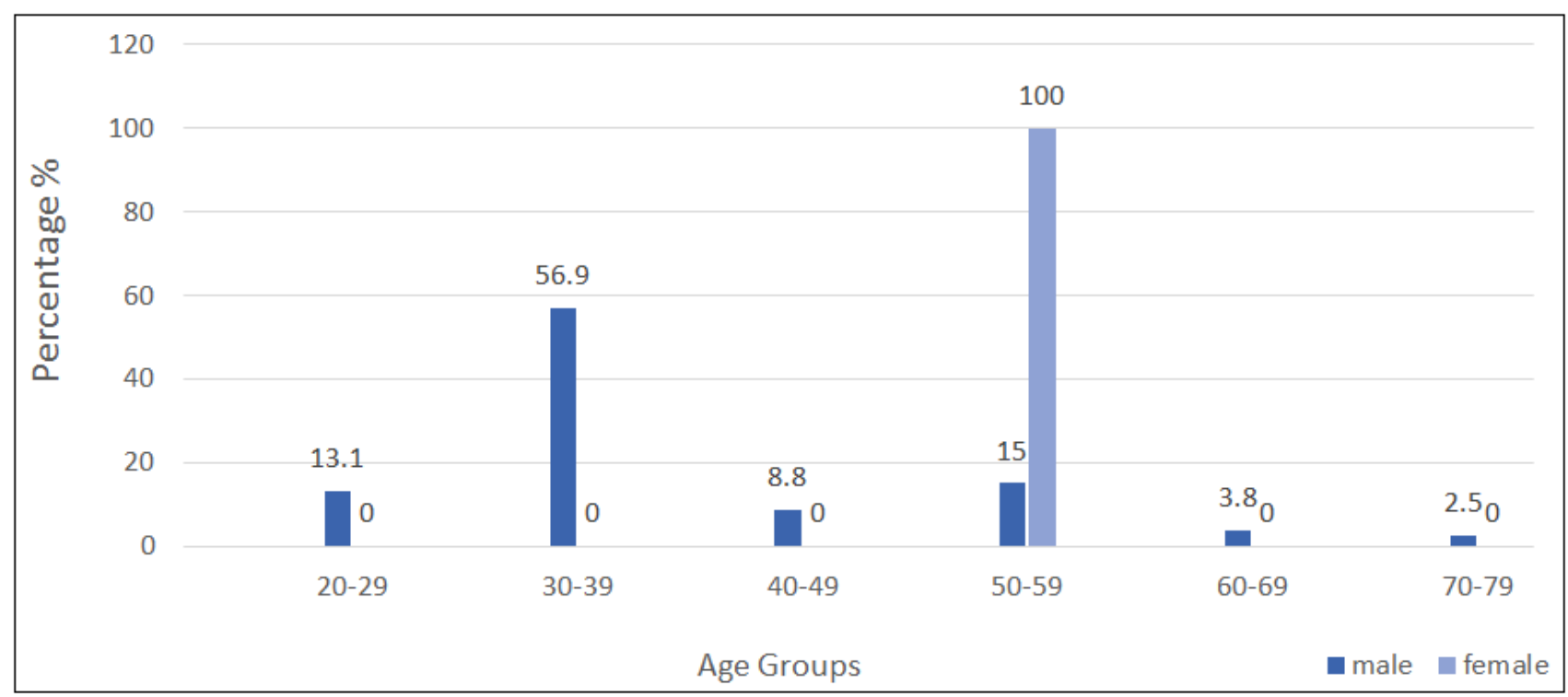

Fig-1: The Prevalence of CAD among smoker patients in relation to Age groups and Gender

About the additional Risk Factors for CAD in smoker patients, the most frequently observed risk factor was dyslipidemia. The prevalence of their lipid parameters were shown as, $53.7 \%$ with high levels of LDL, 31.7\% with low levels of HDL and high levels of Total cholesterol and $29.3 \%$ with high levels of Triglyceride. The mean concentration of LDL was $126.8 \pm 24.2 \mathrm{mg} / \mathrm{dl}$ in males and $147 \pm 9.2 \mathrm{mg} / \mathrm{dl}$ in females, the mean concentration of HDL was 44.3 $\mathrm{mg} / \mathrm{dl}$ and $44.5 \mathrm{mg} / \mathrm{dl}$ in males and females respectively. While the mean concentration of TC was higher in females $(313.5 \pm 20 \mathrm{mg} / \mathrm{dl})$ than in males $(176.47 \pm 71 \mathrm{mg} / \mathrm{dl})$ and this was statistically significant with a $\mathrm{P}$ value of 0.0001 . Similarly, the mean concentration of TG was higher among females $(216 \pm 36 \mathrm{mg} / \mathrm{dl})$ than in males $(184 \pm 30)$ this also was statistically significant with $\mathrm{P}$ value of 0.043

Figure two shows the mean concentration of lipid parameters in relation to Gender. 


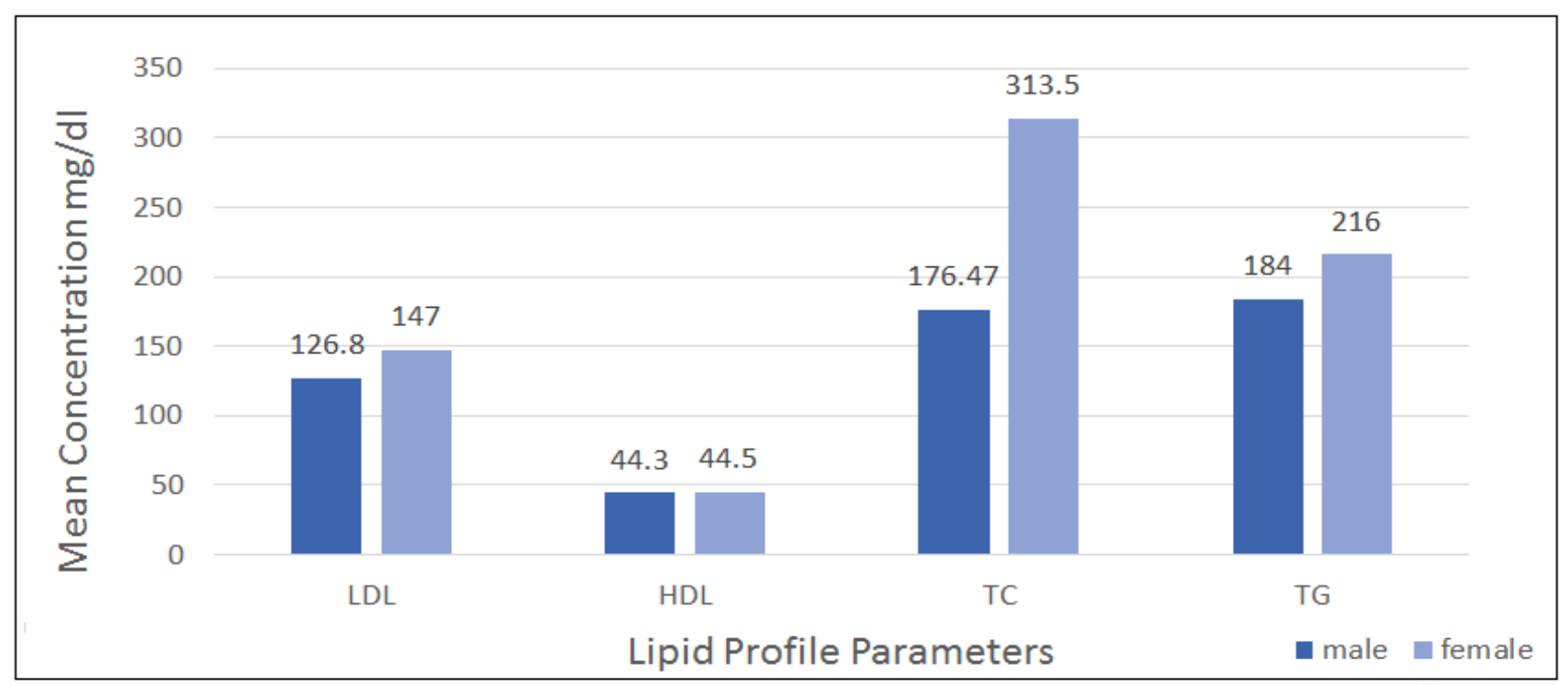

Fig-2: The Mean Concentration of Lipid Profile Parameters in Relation to Gender

Furthermore, the prevalence of Other traditional risk factors for CAD in smoker patients was, Positive Family History of CAD (40.2\%), Hypertension (37.8\%), and Diabetes Mellitus (29.3\%). The prevalence of Undiagnosed DM among smoker patients with CAD was $4.8 \%$, in which they were unaware of their Blood Sugar level, but upon performing the basic investigations- $\mathrm{HbA1c}$, it was observed that they were from the diabetic range. The prevalence of the risk factors among male patients was $37.5 \%$ with hypertension, $40 \%$ with positive family history for CAD and $28.7 \%$ with DM. and this was statistically not significant with $\mathrm{P}$ value of $>0.5$

One interesting point about the additional risk factors for CAD in smoker patients among 30-39 group of age was, $48.5 \%$ were with Positive Family History ( $\mathrm{P}$ is 0.037 ), $45.8 \%$ was $\mathrm{DM}$ ( $\mathrm{P}$ is 0.002 ), and $48.4 \%$, Hypertensive ( $\mathrm{P}$ is 0.002 ), 55.8\% was with Low levels of HDL ( $\mathrm{P}$ is 0.4$), 51.1 \%$ was with high levels of LDL ( $\mathrm{P}$ is 0.01$), 44.2 \%$ was with high levels of Total Cholesterol ( $\mathrm{P}$ is 0.024$)$ and $47.9 \%$ was with high levels of Triglyceride ( $\mathrm{P}$ is 0.6 ).

This clarifies that smoker patients belonging an age group of 30-39 years old with $\mathrm{CAD}$, have the most common risk on their cardiovascular health in addition to their smoking habit. Table one clarifies the prevalence of most common risk factors of CAD in smoker patients belonging to the critical-young- group of age (30-39 years).

Table-1: The prevalence of Most Common risk factors of CAD is Smoker Patients belonging to age group of 30-39 years

\begin{tabular}{|l|l|l|}
\hline Risk Factors & Prevalence (\%) & P value \\
\hline Hypertension & 48.4 & $\mathrm{P}=0.002$ \\
\hline DM & 45.8 & $\mathrm{P}=0.002$ \\
\hline Positive Family History & 48.5 & $\mathrm{P}=0.037$ \\
\hline High LDL & 51.1 & $\mathrm{P}=0.01$ \\
\hline Low HDL & 55.8 & $\mathrm{P}=0.4$ \\
\hline High TC & 44.2 & $\mathrm{P}=0.024$ \\
\hline High TG & 47.9 & $\mathrm{P}=0.6$ \\
\hline
\end{tabular}

Based on their ECG changes, $61.3 \%$ of all the smoker male patients with CAD was presented with STEMI, and $22.5 \%$ presented with NSTEMI. On the other hand, the prevalence of STEMI and NSTEMI among female smoker patients with CAD was $50 \%$ for both ECG presentations. And this was statistically not significant showing $P$ value of 0.3 . All the included smoker patients with CAD have underwent Coronary Angiography and Percutaneous Coronary Intervention according to their CoA status, about $79.3 \%$ of them all had occlusive disease, only $19.3 \%$ was with Non- occlusive disease and $1.2 \%$ with abnormal coronary characteristic. Shedding light on the angiographic profile of smoker patients with CAD, their results showed that, the most common occluded artery among male smoker patients was LAD with a prevalence of $43.8 \%$ followed by the second most common occluded artery, RCA with a prevalence of $13.8 \%$, on the other hand female patients had high prevalence of LCX artery occlusion $(50 \%)$ and this was statistically significant with a $\mathrm{P}$ value of 0.013 . Table two summarizes the angiographic profile of Smoker patients with CAD. 
Table-2: Prevalence of Obstructive Coronary Lesions in Smoker Patients. $(P=0.013)$

\begin{tabular}{|l|l|l|}
\hline \multirow{3}{*}{ Single Vessel Disease } & Name of the Occluded Artery & Prevalence in \% \\
\cline { 2 - 3 } & LAD & $53.8 \%$ \\
\cline { 2 - 3 } & RCA & $16.8 \%$ \\
\cline { 2 - 3 } & LCX & $7.69 \%$ \\
\cline { 2 - 3 } & LMS & $1.5 \%$ \\
\cline { 2 - 3 } & OM & $1.5 \%$ \\
\cline { 2 - 3 } & D1 & $3.02 \%$ \\
\hline Double Vessel Disease & & $4.6 \%$ \\
\hline Triple Vessel Disease & & $10.7 \%$ \\
\hline
\end{tabular}

The prevalence of presenting symptom among smoker patients with CAD was, $65.5 \%$ with chest pain, $62.2 \%$ with Shortness of Breath, $11 \%$ with palpitation, $35.4 \%$ with Nausea and Vomiting and only $9.8 \%$ presented with atypical symptoms. The prevalence of symptoms of CAD in smoker patients was mostly significant among age group of 30-39 years' old, in which $63.7 \%$ of this age group (30-39) presented with Shortness of Breath $(\mathrm{P}=0.008), 46.6 \%$ presented with
Nausea and Vomiting $(\mathrm{P}=0.02), 39.6 \%$ had radiation of the pain to Back and in-between Shoulders ( $\mathrm{P}=$ $0.02), 37.5 \%$ presented with atypical Symptoms $(\mathrm{P}=$ $0.007), 50 \%$ presented with Palpitation $(\mathrm{P}=0.4)$, and $59.3 \%$ presented with chest pain $(\mathrm{P}=0.1)$

Table-3 summarizes the prevalence of the presenting symptoms of CAD in smoker patients among 30-39 years of age.

Table-3: The Prevalence of Symptoms in Smoker Patient with CAD Belonging to Age Group of 30-39 Years Old

\begin{tabular}{|l|l|l|}
\hline Symptoms & Prevalence \% & P value \\
\hline Chest pain & 59.3 & $\mathrm{P}=0.1$ \\
\hline SOB & 63.7 & $\mathrm{P}=0.008$ \\
\hline Palpitation & 50 & $\mathrm{P}=0.4$ \\
\hline Nausea and Vomiting & 46.6 & $\mathrm{P}=0.02$ \\
\hline Radiating Pain to in between shoulders & 39.6 & $\mathrm{P}=0.02$ \\
\hline Atypical symptoms & 37.5 & $\mathrm{P}=0.007$ \\
\hline
\end{tabular}

\section{DISCUSSION}

$\mathrm{CAD}$ has been known to be a disease in which multiple factors like Smoking, Dyslipidemia, Hypertension, Diabetes Mellitus and positive Family History play an important role. Smoking has been shown to be a major dominant modifiable risk factor in patients with established CAD [37-39]. Pais et al., showed that Smoking more than 10 bids in a day results in a four times increase in the chances of developing $\mathrm{CAD}$, and with the presence of additional risk factors the risk increases [40]. Smoking is a globally wellestablished risk factor for CAD, smokers with Ischemic Heart disease (IHD) also have higher incidence of death and other adverse events [23-28]. Kannel et al., found that in patients included in Framingham Heart Study, the relative risk for CAD was about three times higher in smoker patients than non-smokers [41].

It is therefore important to study and analyze the impacts of smoking in patients with established CAD and effects of it on clinical events in patients with complex coronary lesions to better understand the preventive mechanism [29]. In this present study the prevalence of smoker patients with established CAD were $97.6 \%$ male and a very minority portion of $2.4 \%$ were females. The role of estrogens and androgens as cardio protective markers, may help explain such sex dimorphisms, being involved in cardiac function, endothelial function and vascular tone [30]. The result of other studies that have been performed shows the same results as present study in which the ratio was more in males than females, in other word, just below one in five male deaths and one in ten female deaths were attributed to CAD. Women tend to present with coronary artery disease later in life, and even when they present young they tend to receive less evidence-based treatment than their male counterparts. Some studies reported that gender is an independent risk factor for worse outcomes [31]. Focusing on the Age groups among smoker patients included in this present study, we pointed out that majority of the male smoker patients with established CAD were younger (30-39 years of age) while smoker female patients tend to experience $\mathrm{CAD}$ at an older age (50-59 years of age) mostly including the menopausal age group. Smoking habit usually lags in female by 10-20 years than males [32]. These finding were established as well in a study that has been enrolled in London [31]. Another study conducted in Italy showing the same results in which smoking habit among patients with CAD was $24 \%$ males and $7 \%$ female [32]. About the additional risk factors in smoker patient with established CAD, the results of our study confirmed that $53.7 \%$ was with high LDL $31.7 \%$ was with low HDL and high Total Cholesterol and $29.3 \%$ was with high levels of Triglyceride. Results of another study which has been enrolled showed that smokers with established CAD have higher levels of LDL, TC and lower HDL levels, 
and it claimed that smoking could promote atherosclerosis, in part, in patients with established CAD, by its effect on lipid profile [33]. Smoking as it increases the oxidative modification of LDL, Feri et al., observed that exposure of human plasma to the gas phase of cigarette smoke caused oxidative modification of LDL by reducing the plasma activity of Paraxonase enzyme, which is protective against LDL oxidation [34]. However, another study, in which their results are in concordance with the present study, that has been performed in Iran and the results showed that $50 \%$ of them had high levels of LDL, while they had higher levels of TG $(41.9 \%)$ than our study $[35,36]$. The prevalence positive family history among smoker patients for CAD, in this present study was $40.2 \%$ Recently the genetic predisposing was found to be the development of CAD in individuals exposed to cigarette smoke [22]. Interestingly a recent study has concluded that the increased risk of CAD in male smoker patients, has a genetic component, being more evident in male carrying apolipoprotein E epsilon 4 alleles [42]. On the other hand, The Framingham study failed to demonstrate a positive correlation between smoking and CAD among females [43]. The results of our study showed that the majority of smoker patients were male $(97.6 \%)$ and a minor portion were female $(2.4 \%)$. One of the additional and frequently seen risk factors of CAD among smoker patients was DM, in which the prevalence of it was $(34.1 \%)$ A positive relationship between smoking and DM- as a major independent risk factor for CAD- has also been recently confirmed by a large prospective cohort study, among them male smokers had a $(45 \%)$ higher diabetic rates than those who had never smoked, the corresponding increase for women was (74\%) [44] the results of our study showed similar manners of distribution, in which the prevalence of DM was higher among females (50\%) than males $(28.7 \%)$. In this present study, $(37.8 \%)$ of the smoker patients with established CAD, were hypertensive. Sofia Study and EUROSPIRE III have shown that hypertension has been seen as one of the major risk factors of CAD [45].

Another study has been conducted and their results are going parallel to the results of current study, in which the prevalence of hypertension among smoker patients was about 39\% [46]. In our study we observed that Anterior Wall Myocardial Infarction-AWMI was the most common type which owes to LAD artery (43.8\%). Then followed by RCA (13.8\%). The results go parallel to another study that has been performed in India [47]. Our study revealed a preponderance of Single and Triple Vessel Disease among both genders, while Double Vessel Disease only in male gender. The incidence of Angiographic normal coronary arteries in smoker patients with established CAD, which has been defined as Ischemia with no Obstructive Coronary Artery Disease (INOCAD)- in various studies was 9\% to $17 \%$ [48] which appears to be within the same range of our results $(15.9 \%)$ the causes could be due to coronary spam, spontaneous recanalization or thrombosis with reperfusion. Upon the angiographic finding of them, it was noted that male patients mostly had occlusion in LAD while females had occlusion in LCX artery.

The results about the ECG finding in smoker patients with CAD showed that $61.3 \%$ of them presented with STEMI and $22.5 \%$ with NSTEMI. A recent study has shown that Smoking was associated with an eightfold increased risk of acute STEMI and smokers tend to have STEMI at a younger age than non-smokers therefore, Further efforts are needed to reduce smoking [49].

\section{CONCLUSION}

The importance of this study lies in the fact that it revealed a distinct association of smoking habit and traditional risk factors for CAD. The study highlighted the pathological effects of smoking and its contribution along with other risk factors for developing CAD. In view of its high prevalence and increased risk contribution, smoking should be considered as the most common modifiable risk factors, as it enhances and accelerates the pathophysiology of CAD. We concluded that the effect of smoking has altered the symptoms of presentation to be more common among younger (3039 years old) patients. This clarifies that smoking causes CAD to happen earlier than in non-smoker patients.

\section{Financial support and sponsorship: Nil.}

Conflicts of interest: There are no conflicts of interest.

Disclosure: There are no relationships with industry.

Founding: This Article has not been founded by any organization/Institution and has no Financial Support.

\section{Acknowledgment}

We would like to thank all the people who played an important role in accomplishing this work. We would like to appreciate the staff of SSH-Cardiac Centre who were supportive in collecting the data.

\section{Study Limitations}

Our study had some limitations within which some of the consecutive patients had to be excluded from the population because of some missing data.

\section{REFERENCES}

1. Lopez, A. D., \& Murray, C. C. (1998). The global burden of disease, 1990-2020. Nature medicine, 4(11), 1241-1243.

2. Black, H. R. (1995). Smoking and cardiovascular disease. In: Laragh, J. H., \& Brenner B. M., editors. Hypertension: Pathophysiology, Diagnosis andManagement. 2nd edition. New York, NY: Raven Press Ltd. 2621-47. 
3. Pearl, R. (1938). Tobacco smoking and longevity. Science, 87(2253), 216-217.

4. Doll, R., \& Hill, A. B. (1956). Lung cancer and other causes of death in relation to smoking. British medical journal, 2(5001), 10711081 .

5. Hammond, E. C., \& Horn, D. (1958). Smoking and death rates: report onforty-four months of follow-up of 187,783 men. II. Death rate bycause. JAMA, 166:1294-308.

6. Doll, R., \& Peto, R. (1976). Mortality in relation to smoking: 20 years' observations on male British doctors. BMJ. 2:1525-36.

7. United States Department of Health. (1964). Education and Welfare, Public Health Service. Smoking and Health: Report of the Advisory Committee to the Surgeon General of the Public Health Service(PHS Publication No. 103). Washington, DC: Government Printing Office.

8. Doll, R., Gray, R., Hafner, B., \& Peto, R. (1980). Mortality in relation to smoking: 22 years' observations on female British doctors. Br Med J, 280(6219), 967-971.

9. Willett, W. C., Green, A., Stampfer, M. J., Speizer, F. E., Colditz, G. A., Rosner, B., ... \& Hennekens, C. H. (1987). Relative and absolute excess risks of coronary heart disease among women who smoke cigarettes. New England Journal of Medicine, 317(21), 1303-1309.

10. Price, J., Mowbray, P. I., Lee, A. J., Rumley, A., Lowe, G. D. O., \& Fowkes, F. G. R. (1999). Relationship between smoking and cardiovascular risk factors in the development of peripheral arterial disease and coronary artery disease; Edinburgh Artery Study: Edinburgh Artery Study. European heart journal, 20(5), 344-353.

11. Jonas, M. A., Oates, J. A., Ockene, J. K., \& Hennekens, C. H. (1992). Statement on smoking and cardiovascular disease for health care professionals. American Heart Association. Circulation, 86(5), 1664-1669.

12. Centers for Disease Control and Prevention. (2002). Annual smoking-attributable mortality, years of potential life lost, and economiccostsUnited States, 1995-1999. MMWR Morb Mortal Wkly Rep. 5:300-303.

13. Negri, E., Franzosi, M. G., La Vecchia, C., Santoro, L., Nobili, A., \& Tognoni, G. (1993). Tar yield of cigarettes and risk of acute myocardial infarction. GISSI-EFRIM Investigators. British Medical Journal, 306(6892), 1567-1570.

14. Bolinder, G., Alfredsson, L., Englund, A., \& De Faire, U. (1994). Smokeless tobacco use and increased cardiovascular mortality among Swedish construction workers. American Journal of Public Health, 84(3), 399-404.

15. Amen, S. O., Baban, S. T., Yousif, S. H., Hawez, A. H., Baban, Z. T., \& Jalal, D. M. F. (2020). Prevalence of the most frequent risk factors in Iraqi patients with acute myocardial infarction. Medical Journal of Babylon, 17(1), 618.

16. Barua, R. S., \& Ambrose, J. A. (2013). Mechanisms of coronary thrombosis in cigarette smoke exposure. Arteriosclerosis, thrombosis, and vascular biology, 33(7), 1460-1467.

17. Winniford, M. D. (1990). Smoking and cardiovascular function. Journal of hypertension. Supplement: official journal of the International Society of Hypertension, 8(5), S17-23.

18. Benowitz N. L. (1997). The role of nicotine in smoking-related cardiovascular disease. Preventive medicine, 26(4):412-417.

19. Achari, V., \& Thakur, A. K. (2004). Association of major modifiable risk factors among patients with coronary artery disease-a retrospective analysis. JAPI, 52, 103-108.

20. Das, B., Daga, M. K., \& Gupta, S. K. (2007). Lipid Pentad Index: A novel bioindex for evaluation of lipid risk factors for atherosclerosis in young adolescents and children of premature coronary artery disease patients in India. Clinical biochemistry, 40(1-2), 18-24.

21. Goel, P. K., Bharti, B. B., Pandey, C. M., Singh, U., Tewari, S., Kapoor, A., ... \& Sinha, N. (2003). A tertiary care hospital-based study of conventional risk factors including lipid profile in proven coronary artery disease. Indian heart journal, 55(3), 234.

22. Ramsdale, D. R., Faragher, E. B., Bray, C. L., Bennett, D. H., Ward, C., \& Beton, D. C. (1985). Smoking and coronary artery disease assessed by routine coronary arteriography. Br Med J (Clin Res Ed), 290(6463), 197-200.

23. Critchley, J. A., \& Capewell, S. (2003). Mortality risk reduction associated with smoking cessation in patients with coronary heart disease: a systematic review. Jama, 290(1), 86-97.

24. Jha, P., Ramasundarahettige, C., Landsman, V., Rostron, B., Thun, M., Anderson, R. N., ... \& Peto, R. (2013). 21st-century hazards of smoking and benefits of cessation in the United States. New England Journal of Medicine, 368(4), 341-350.

25. Sakata, R., McGale, P., Grant, E. J., Ozasa, K., Peto, R., \& Darby, S. C. (2012). Impact of smoking on mortality and life expectancy in Japanese smokers: a prospective cohort study. BMj, 345, e7093.

26. Ambrose, J. A., \& Barua, R. S. (2004). The pathophysiology of cigarette smoking and cardiovascular disease: an update. Journal of the American college of cardiology,43(10), 17311737.

27. Ezzati, M., Henley, S. J., Thun, M. J., \& Lopez, A. D. (2005). Role of smoking in global and regional cardiovascular mortality. Circulation, 112(4), 489497.

28. Thun, M. J., Carter, B. D., Feskanich, D., Freedman, N. D., Prentice, R., Lopez, A. D., ... \& Gapstur, S. M. (2013). 50-year trends in smoking- 
related mortality in the United States. $\mathrm{N}$ engl $\mathbf{J}$ med, 368, 351-364.

29. Zhang, Y. J., Iqbal, J., Van Klaveren, D., Campos, C. M., Holmes, D. R., Kappetein, A. P., ... \& Onuma, Y. (2015). Smoking is associated with adverse clinical outcomes in patients undergoing revascularization with PCI or CABG: the SYNTAX trial at 5-year follow-up. Journal of the American College of Cardiology, 65(11), 11071115.

30. Rosano, G. M. C., Spoletini, I., \& Vitale, C. (2017). Cardiovascular disease in women, is it different to men? The role of sex hormones. Climacteric, 20(2), 125-128.

31. Khamis, R. Y., Ammari, T., \& Mikhail, G. W. (2016). Gender differences in coronary heart disease. Heart, 102(14), 1142-1149.

32. Peto, R., Lopez, A. D., Boreham, J., Thun, M., Heath Jr, C., \& Doll, R. (1996). Mortality from smoking worldwide. British medical bulletin, 52(1), 12-21.

33. Craig, W. Y., Palomaki, G. E., \& Haddow, J. E. (1989). Cigarette smoking and serum lipid and lipoprotein concentrations: an analysis of published data. British medical journal, 298(6676), 784-788.

34. Frei, B., Forte, T. M., Ames, B. N., \& Cross, C. E. (1991). Gas phase oxidants of cigarette smoke induce lipid peroxidation and changes in lipoprotein properties in human blood plasma. Protective effects of ascorbic acid. Biochemical Journal, 277(1), 133-138.

35. Hatmi, Z. N., Tahvildari, S., Motlag, A. G., \& Kashani, A. S. (2007). Prevalence of coronary artery disease risk factors in Iran: a population based survey. BMC cardiovascular disorders, 7(1), 32.

36. González-Pacheco, H., Vargas-Barrón, J., Vallejo, M., Piña-Reyna, Y., Altamirano-Castillo, A., Sánchez-Tapia, P., \& Martínez-Sánchez, C. (2014). Prevalence of conventional risk factors and lipid profiles in patients with acute coronary syndrome and significant coronary disease. Therapeutics and clinical risk management, 10, 815-823.

37. Panwar, R. B., Gupta, R., Gupta, B. K., Raja, S., Vaishnav, J., Khatri, M., \& Agrawal, A. (2011). Atherothrombotic risk factors \& premature coronary heart disease in India: a case-control study. The Indian journal of medical research, 134(1):26-32.

38. Shankar, S. R., Jaishankar, S., \& Raghu, K. (2002). Risk and biochemical profile of acute myocardial infarction in a young population. Ind Heart J. 54:541.

39. Tewari, S., Kumar, S., Kapoor, A., Singh, U., Agarwal, A., Bharti, B. B., ... \& Sinha, N. (2005).
Premature coronary artery disease in North India: an angiography study of 1971 patients. Indian Heart J. 57:311-8.

40. Pais, P., Fay, M. P., \& Yusuf, S. (2001). Increased risk of acute myocardial infarction associated with beedi and cigarette smoking in Indians: final report on tobacco risks from a case-control study. Indian heart journal, 53(6), 731-735.

41. Kannel, W., McGee, D., \& Castelli, W. (1984). Latest perspectives on cigarette smoking and cardiovascular disease: the Framingham Study. Journal of Cardiac Rehabilitation, 4(7), 267-277.

42. Humphries, S. E., Talmud, P. J., Hawe, E., Bolla, M., Day, I. N., \& Miller, G. J. (2001). Apolipoprotein E4 and coronary heart disease in middle-aged men who smoke: a prospective study. The Lancet, 358(9276), 115-119.

43. Seltzer, C. C. (1989). Framingham study data and "established wisdom" about cigarette smoking and coronary heart disease. Journal of clinical epidemiology, 42(8), 743-750.

44. Will, J. C., Galuska, D. A., Ford, E. S., Mokdad, A., \& Calle, E. E. (2001). Cigarette smoking and diabetes mellitus: evidence of a positive association from a large prospective cohort study. International journal of epidemiology, 30(3), 540-546.

45. Kotseva, K., Wood, D., De Backer, G., De Bacquer, D., Pyörälä, K., Keil, U., \& EUROASPIRE Study Group. (2009). EUROASPIRE III: a survey on the lifestyle, risk factors and use of cardioprotective drug therapies in coronary patients from 22 European countries. Heart, 16(2), 121-137.

46. James, C. (2013). Risk factors for coronary artery diseases: a study among patients with ischemic heart disease in Kerala. Heart India, 1(1), 7-11.

47. Sinha, S. K., Krishna, V., Thakur, R., Kumar, A., Mishra, V., Jha, M. J., ... \& Afdaali, N. (2017). Acute myocardial infarction in very young adults: A clinical presentation, risk factors, hospital outcome index, and their angiographic characteristics in North India-AMIYA Study. Arya Atherosclerosis, 13(2), 79.

48. Wolfe, M. W., \& Vacek, J. L. (1988). Myocardial infarction in the young. Angiographic features and risk factor analysis of patients with myocardial infarction at or before the age of 35 years. Chest. 94(5): 926-30.

49. Lloyd, A., Steele, L., Fotheringham, J., Iqbal, J., Sultan, A., Teare, M. D., \& Grech, E. D. (2017). Pronounced increase in risk of acute ST-segment elevation myocardial infarction in younger smokers. Heart, 103(8), 586-591. 